\title{
Un repaso teórico (exhaustivo o no) al debate de la "muerte del cine" en el cine contemporáneo
}

\section{A Theorical Review (Thorough or Not) to the Discussion of the "Death of Cinema" in the Contemporary Cinema}

\author{
José Miguel Santa Cruz \\ Universidad de Barcelona \\ josesantacruzgrau@gmail.com
}

\section{Resumen}

En el clima actual de los estudios de cine, el tema de la «muerte del cine» parece un debate con ribetes apocalípticos y profundamente nostálgico. Algo que pertenece exclusivamente a la última década del siglo XX -con sus proyecciones y sus retrocesos necesarios hacia la primera década del siglo XXI y los años ochenta respectivamente-. No obstante ello, fue un debate que convocó fuertes puntos de vista y finos dispositivos discursivos que intentaban comprender procesos complejos sobre la naturaleza cinematográfica, los cambios del consumo cultural, las transformaciones estéticas, la emergencia de nuevas formas de comprender el cine, etc. En este sentido nos interesa destacar que este tópico ha sido un motor reflexivo que expandió las fronteras de la propia teoría cinematográfica.

Palabras clave: teoría del cine, cine contemporáneo, muerte del cine.

\section{Abstract}

In the current climate of the film studies, the subject about the «death of cinema» appear as a discussion with apocalyptic signs and deeply nostalgic. Something that appear to belong to only to the last decade of 20th Century -with necessary projections and relapse to the first decade of 21st century and 1980s respectively-. But, it was a discussion that convened strong views and discursive devices stylized, that tried understand processes complex about: the cinematic nature, the changes of the cultural consumption, the aesthetics and discursive transformations, the burst in of new kind of understand of the cinema, etc. In this sense, we wish to emphasize that this topic has been a reflexive motor that expanded the frontiers of the film theory itself.

Keywords: Cinema Theory, Contemporary Cinema, Death of Cinema. 
Lo cinematográfico ha pensando su muerte desde muy temprana data, ya Orson Wells planteaba «Creo en la muerte del cine. Miren la energía desesperada con que tratan de animarlo: ayer, por medio del color; hoy, con las tres dimensiones. No le doy más de cuarenta años». Los hermanos Lumière lo consideraba una invención sin mayor futuro y varios intelectuales de la primera década auguraba un rápido óbito al que se convertiría en el arte de las masas del siglo XX. En ello podríamos apelar su relación interna con la modernidad, es decir, ensayando una y otras vez las formas de su ocaso, exponiendo sintomáticamente sus límites. No obstante ello, desde la consolidación del campo audiovisual por fuera de las formas cinematográficas en los años ochenta, principalmente con la tecnología del video analógico y la expansión televisiva, estos planteamientos se han multiplicado a una velocidad cada vez más grande vehiculizados por la revolución digital.

En una reciente publicación de Antoine de Baecque y Philippe Chevallier, Dictionnaire de la pensée du cinéma [Diccionario del pensamiento de cine] (2012), De Baecque propone que la discusión sobre la muerte del cine es un síntoma de su vitalidad, ya que "le septième art, peut-être parce qu'il s'estimait le plus grand, s'est toujours cru le plus éphémère" $(\mathrm{s} / \mathrm{n} \mathrm{pp} .)^{1}$. Dentro de este contexto, instala que son dos los pensadores -evidentemente franceses- que se han sido los motores de esta discusión: Serge Daney y Jean-Luc Godard ${ }^{2}$. En relación a Daney comprenderá que su dispositivo crítico en la década del ochenta -tras el trauma iconoclasta post-mayo del 68 - podría ser considerado como una especie de pequeño país aislado, una minoría frente a un mar de imágenes y el audiovisual contemporáneo. El cine para el fundador de Trafic se transforma en una carga que intenta sobrellevar aún ahí cuando piensa que se ha vuelto post-publicitario, aún ahí cuando ve una demografía vacía, con salas desterradas al olvido. Según De Baecque, se vuelve parte de una minoría resistente -encarnada en cineastas como Godard, De Oliveira o Jean-Marie Straub-, pero al mismo tiempo, sabe que detrás del fin del cine, está el final de la crítica, ya que ésta se une "autre sphère, le forum électronique mondial, ce pays étrange où tous sont critiques"(s/n pp.) $)^{3}$.

Las perspectivas mortuorias de Daney comenzaron a articularse con fuerza desde su artículo «Du grand au petit ecran» [De la gran a la pequeña pantalla] publicado el 16 de Noviembre 1987 en Libération. En éste se preguntaba fundamentalmente qué se pierde de cine en la televisión, en ese espacio visual que tiene un sospechoso gusto por lo comprimido y confinado. Más allá de la experiencia masiva de la sala, sus liturgias religiosas, como también el patético espectáculo de las salas

1 “el séptimo arte, posiblemente porque se consideraba el más grande, siempre se creyó el más efímero". [Todas las traducciones son nuestras]

2 Las perspectivas de la muerte del cine en la obra de Jean-Luc Godard la veremos más adelante a través del prisma del teórico Matthew Witt.

3 "a otra esfera, el foro electrónico mundial, esta extraña tierra donde todos son críticos". 
vacías que se hacía patente durante toda la década, principalmente en relación a las películas que circulaban en las salas de «arte y ensayo» o «cine arte», tomando en cuenta que la exhibición de un filme en la televisión daba cuenta al mismo tiempo de que era realmente bueno y malo en el propio cine. Hay algo que se había perdido en la televisión que no se solucionaba con el gigantismo del Cinemascope y había algo perdido en las imágenes cinematográficas que no se encontraba en el enanismo de la pantalla televisiva.

Para Daney la potencia de los filmes fundamentales no se pierde por un simple cambio de formato, eso implicaría asumir una cultura cinematográfica muy débil, lo que se extravía en las producciones televisivas de ficción-que reemplazan las narrativas cinematográficas- es el dominio de las distancias, tanto en relación de la cámara frente al objeto y los actores que se cristaliza en la anulación de la distancia focal en el exceso del uso del zoom, pero también de una forma de ver el cine que es suprimida por la estética del zapping, esa dimensión táctil que se ha instalado entre el espectador y la imagen cinematográfica-audiovisual. Esto es lo que ha posibilitado la televisión en relación a las imágenes en movimiento, una reducción constante de las distancias que habían constituido parte fundamental de la gramática cinematográfica.

La experiencia cinematográfica será su objeto en su artículo «Pour une cinédémographie» [Por un cine-demográfico], también publicado en Libération, el 13 septiembre de 1988. Esta vez instalará una mirada retrospectiva y en cierta medida melancólica. Daney desarrolló la relación interna y dependiente del cine moderno con la ausencia de las masas en las salas de cine, en el contexto del auge del crecimiento económico capitalista-neoliberal y de un incipiente individualismo cultural, que se verá consumado en un última instancia en un «cine de autor» que buscó un público equivalente a él mismo. Este proceso que Daney ubica en las salas durante los años setenta también lo encontrará en las propias imágenes de los cineastas. Lo que entenderá por "a different era, something like a post-cinema (which is also posttelevision and post-advertising) characterised by this novel situation: many people in just a few (large) theatres want to see films with just a few characters" (Daney Pour une ciné... s/n pp. $)^{4}$.

Detrás de este proceso de despoblamiento tanto en las salas a mano del cine moderno y de la imagen en los filmes de la industria hollywoodense; trae consigo la idea de que lo que se ha extraviado o lo que caracterizaría al cine después de lo moderno, es un cine que ha extraído a lo humano como índice, tanto ahí cuando eran las masas convocadas en la pantalla, esa expresión de un espacialidad a conquistar en los procesos de modernización como en el mundo interior del individuo,

4 "una era diferente, algo así como un post-cine (que también es post-televisión y post-publicidad) caracterizado por esta nueva situación: muchas personas en tan sólo unos pocos (grandes) teatros quieren ver filmes con sólo unos pocos personajes". 
territorio soberano del cine moderno, a causa de la desproporción del mundo con respecto al individuo. Poniendo al cine en una frontera "between human and non-human. Sterile, between man and beast, between man and gods. To tell their story is showing to which extent they have no history" (Daney Pour une ciné... s/n pp. $)^{5}$. Es por ello que Daney se pregunta si no será la demografía la nueva ciencia que debiera fundirse con la teoría cinematográfica para pensar al cine -en ello el título de su artículo-.

Por último, en «Du défilement au défilé» [Del proyector al desfile], artículo publicado en La recherche photographique $\mathrm{N}^{\circ} 7$ en 1989, la hipótesis que se jugará Daney será que a mediados de los años setenta existió una quiebre en la imagen cinematográfica, que respondió a un proceso de movilización del espectador sujeto a los medios audiovisuales que terminó inmovilizando el interior de la propia imagen cinematográfica. "Audiovisual consumption (television, of course, but also video installations and things of the sort) tends to prove that we have learned how to pass by images the way people must have learned to pass by lighted window displays

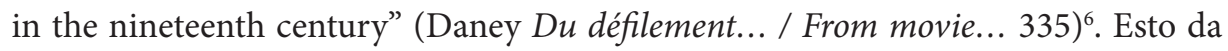
paso a un cine como «iluminación» de objetos deseables, en que las bobinas de cine se transforman en bucles comerciales o publicitarios, recuperando su vocación de presentación de objetos que había tenido en sus primeros años de existencia. Pero la inmovilidad cinematográfica no será sólo una imagen fija que se fue instalado como una unidad de muerte en el cine en la década del setenta, sino la imposibilidad de encontrar es movimiento que pueda organizarlas, ese montaje que se extrae del propio material, impidiendo encontrar en ello algo que las contenga en una totalidad. Las imágenes se van colocando una al lado de la otra, sin transformarse en causa o efecto de las mismas, agotando su movimiento en ellas mismas sin poder traspasarla a la siguiente. Asimismo las personas -aún en su condición de actores- pasan frente a cámara pero no habitan ese espacio que pretende contener o construir la imagen, ese pasar -acción en movimiento- muere en sí mismo, es un desfile de cuerpos, una pasarela publicitaria para un cuerpo -la mayoría de las veces- anónimo.

Para Daney en 1989 plantear que el cine ha sido contaminado por el lenguaje de la publicidad, es una discusión desfasada en el tiempo, eso ya se había sancionado en un filme como Diva (1981), de Jean-Jacques Beineix. El problema era identificar esas formas posteriores a la negociación de lo publicitario con lo cinematográfico, en lo que entiende en un estadio post-publicitario. "Cinema now inherits prefabricated shots, ready-to-use 'cliches', in short-immobile images” (Daney Du défilement... /

5 "entre lo humano y lo no-humano. Estéril, entre hombre y bestia, entre hombre y los dioses. Para contar sus historias muestran hasta qué punto no tienen historia".

6 "El consumo audiovisual (televisión, por supuesto, pero también instalaciones de video y cosas por el estilo) tienden a demostrar que hemos aprendido a pasar por las imágenes de la manera como la gente debe haber aprendido a pasar por los escaparates iluminados en el siglo XIX". 
From movie... 337) ${ }^{7}$. En este sentido, considera que el cine ha tenido que deshacer el camino hecho, remplazando las preguntas ¿a dónde vamos? ¿Dónde está el movimiento? Para interrogarse por el lugar dónde se ha llegado y desde dónde proviene el movimiento. Esto último es el resultado de la incógnita de la fuerza que lo ha programado, en ello su dependencia actual a la televisión. Así todo el camino del cine -su historia- se muestra como la antesala del gobierno de la imagen publicitaria, ese camino necesario -aunque a veces tedioso para la propia publicidad-por el cual la imagen tuvo que andar para resplandecer en su presente, nublando las fronteras entre el objeto y su representación para su consumo estético. El cine post-publicitario es la consumación de la «muerte del cine» en Daney.

En abril de 1992 Thomas Elsaesser publica en la revista inglesa Sight \& Sound, un artículo titulado «Around Painting and the "End of Cinema" - A Propos Jacques Rivette's La Belle Noiseuse» [En torno a la pintura y el "fin del cine" - A propósito de La bella mentirosa de Jacques Rivette], en este sintomatiza una serie de problemas que habían venido asechando a la teoría cinematográfica francesa -Pascal Bonitzer, Jacques Aumont, Marc Vernet y Raymond Bellour- desde mediados de la década del ochenta, en torno a los límites de lo cinematográfico que se padecía en su relación siempre compleja con la pintura. Elsaesser plantea esta relación de forma benigna desde un inicio, en la medida en que el cine siempre había trabajado como motivo la pintura, sobre todo a la hora de tomar la historias de vida de ciertos pintores como objeto de sus guiones. No obstante, los artículos, libros y conferencias que la intelectualidad francesa publican establecen un problema de mayores consecuencias. Elsaesser lo resume en la idea de que aquella situación cinematográfica llamaba a repensar las formas del cine a través del ojo de la pintura, rechazando de una vez por todas el debate entre arte y cultura popular. Lo que abría su relación conflictiva con el video, la arquitectura y la televisión.

Teniendo como telón de fondo el filme La Belle Noiseuse de Rivette, Elsaesser reconoce en las operaciones de Passion (1982), de Jean-Luc Godard, "in Passion, cinema is the vanishing point between painting on one side, and the video screen and monitor on the other" (s/n pp. $)^{8}$. Desde esta perspectiva ve como el cine de finales de los ochenta e inicios de los noventa está negociando sus formas con otras artes, repensándose asimismo al interior de un régimen estético mayor. Lo que terminará posibilitándole un extenso análisis sobre las estrategias desarrolladas por Rivette en el filme y los problemas discursivos que cruzan el filme: 1) la imposibilidad del autor cinematográfico en constituirse como tal, pero que tiene una necesidad performática de hacerlo. 2) la reflexión sobre la artesanía cinematográfica mediados por las problemáticas representacionales y temporales entre pintura y cine. Esto lleva

7 "El cine ahora hereda planos prefabricados, clichés listos-para-usar, en resumen, imágenes inmóviles".

8 “en Pasión, el cine es el punto de fuga entre la pintura por un lado y la pantalla de video y el monitor por el otro". 
Elsaesser hacia el final de su artículo, a plantear que La Belle Noiseuse "suggests that the change from the photographic image to the digital image is more than a change in technology, or delivery system, but will entail a long and protracted struggle not only over the interpretation of this or that film, but over the meaning of the cinema altogether" (Elsaesser s/n pp.) ${ }^{9}$.

En el segundo párrafo de «El cine después del cine» (1995) Roman Gubern se pregunta si el cine ha muerto efectivamente -siguiendo la línea de lectura de Daney-. Su respuesta es ambigua, si bien planteaba que en la praxis esto no había sucedido, ya que se continuaban produciendo películas que se exhibían en salas de cine, por otro lado, comprendía que el cine como tal -aquello que habían vivido apenas un poco más de una década atrás y había educado a tres generaciones de espectadoreshabía sido remplazado por lo audiovisual. La influencia de la televisión como soporte privilegiado de exhibición de la imágenes contemporáneas contaminó las conquistas propias del lenguaje cinematográfico, que influido por las formas de la ficción televisiva -el ejemplo que utilizará son las teleseries- recayó en una audiovisualidad redundante, mecanizada y simplista, donde cualquier densidad narrativa, visual o psicológica estaba vedada para la fácil comprensión e identificación de un «público infiel». Narrativas carentes de transiciones y tiempos muertos, que eran compensadas a través de la espectacularización de los efectos audiovisuales, de la intensidad en la acción-emoción o con todo a la vez. Gubern vio en esas masas de "prácticas representacionales, comunicativas o estéticas, utilitarias, perversas o triviales, extremadamente heterogéneas, sobre soportes y formatos tan diversificados" (307) la muerte del cine, de aquello que el considera el propio cine. Pero, a su vez, sospechó que existía una prolongación del propio cine "todo lo que existe es hijo o nieto del cine, de su modelo fundacional de un modo de representación que conoció su etapa de esplendor en la época de las grandes salas oscuras" (309). La defunción cinematográfica acontece en su disolución en las formas audiovisuales consolidadas desde los años ochenta del siglo XX, pero, a su vez, el cine sería entonces una matriz representacional y expresiva irrenunciable para todo lo audiovisual contemporáneo.

Al otro lado del atlántico, Susan Sontang en 1996 publica su crónica «The Decay of Cinema» [La decadencia del cine] en el diario New York Times, uno de los textos más citados y trabajados a propósito del tópico de la muerte del cine. Este pequeño texto piensa la muerte cinematográfica en relación a ese tipo particular de relación que había nacido en el cine post-segunda guerra mundial: la cinefilia. Para Sontang a mediados de los noventa las "ordinary films, films made purely for entertainment (that is, commercial) purposes, are astonishingly witless; the vast majority fail resoun-

9 "sugiere que el cambio de la imagen fotográfica a la imagen digital es más que un cambio en la tecnología o sistema de exhibición, sino que implica una larga y prolongada lucha no sólo por la interpretación de tal o cual película, sino por el sentido completo del cine". 
dingly to appeal to their cynically targeted audiences" (s/n pp. $)^{10}$. Nada quedaba ya de esa cultura cinematográfica popular que había sido vaciada por la televisión, de la experiencia «erótica-meditativa» de la sala oscura y del asombro cinematográfico perpetrado en el público desde la entrada del tren en la estación de La Ciotat. Por más que el cine nos enfrente a "assaultive images, and the unprincipled manipulation of images (faster and faster cutting) to make them more attention-grabbing, has produced a disincarnated, lightweight cinema that doesn't demand anyone's full attention" (s/n pp. $)^{11}$.

Sontang pone de manifiesto que el conflicto esencial del cine en general, es el resultante de su dimensión de arte y de entretenimiento, en la medida que la balanza no se desequilibrara éste aún podía sostenerse a sí mismo. Lo que posibilitó que todas las experimentaciones formales acaecidas en Europa desde los años cincuenta hicieran mella en la experiencia moderna del cine. Pero esto se fue desmantelando ya en los años setenta, en lo que comprende como en el plagio y banalización de las búsquedas de los cineastas europeos por parte de los estadounidenses y la inflación de los presupuestos (producción y distribución) por la industria de Hollywood en los años ochenta. Amnos procesos terminaron por asfixiar al propio cine, desnaturalizando su propia promesa en las manos de unos éxito de taquilla, que no podían convocar la fuerza de las imágenes de Hans-Jurgen Syberberg, Aleksandr Sokurov o el propio Godard. Es en ese contexto que la cinefilia moderna -comprendida por Sontang como ese amor por los filmes, que se sostiene en que cada uno de ellos es único y que debería ser comprendido como un objeto poético antes que nada- se ha muerto y "if cinephilia is dead, then movies are dead too... no matter how many movies, even very good ones, go on being made" (s/n pp.) $)^{12}$.

El rumor de la agonía cinematográfica también está presente en los dos intercambios epistolares que se encuentra en el libro editado por Jonathan Rosenbaum y Adrian Martin, Mutaciones de cine contemporáneo (2003). El primero de estas conversaciones epistolares titulada «Mutaciones del cine contemporáneo. Cartas de (y para) algunos hijos de los años sesenta» que ocurrió entre 1997 y 1998, convocó a los críticos Kent Jones, Alexander Horwath, Nicole Brenez y Adrian Martin, junto al teórico Raymond Bellour. La segunda titulada «Mutaciones del cine contemporáneo. Segunda ronda de una correspondencia», citó a los críticos Quintín [Eduardo Antín], Mark Peranson, Brenez, Martin y Rosenbaum. En ellas varios autores evaluaron las premisas asociadas a la muerte y generalmente tras sopesarlo con la vitalidad de la

10 "películas ordinarias, películas realizadas exclusivamente para el entretenimiento (es decir, comerciales), son asombrosamente estúpidas, la gran mayoría fracasan estrepitosamente al apelar cínicamente a su público objetivo”.

11 "imágenes agresivas y a la manipulación sin escrúpulos de las imágenes (más rápidas y cortes más rápidos) para hacerlas más llamativas, se ha producido una descorporalización, cine sin peso que no demanda la atención de nadie".

12 "si la cinefilia ha muerto, las películas están muertas también... no importa cuantas películas, incluso muy buenas, se sigan haciendo". 
producción contemporánea se rehusaron a dar por cierto su defunción. Un ejemplo de esto lo encontraremos en la carta de Rosenbaum, que planteó "la «muerte del cine» y/o de la cinefilia se ha vuelto una moneda corriente; una postura desde luego fácil de sostener en una país [EE.UU.] donde todavía no se ha distribuido correctamente ni una sola película de Hou Hsiao-hsirn, Edward Yang, Abbas Kiarostami o Mohsen Makhmalbaf" (36).

Dentro de este contexto, serán las perspectivas de Brenez las que más nos interesen, la teórica francesa comprende el tópico de la «muerte del cine» no como el resultado de un estado de la producción cinematográfica, sino como un motivo estético o un tema «melancólico y grandilocuente» que algunos cineastas requerían para realizar sus filmes. Según Brenez "era un tema encantador, eso es cierto. Cuando lo abandonaron, las películas de [Win] Wenders se volvieron de alguna forma insoportable de ver, y cuando Godard quiso hacer de nuevo una película sobre (o con) la juventud, una obra que era crítica pero sin melancolía, hizo la que es, a mi parecer, su primera y única película mala, For Ever Mozart [Para siempre Mozart] (1996)" (en Rosenbaum y Martin 65). Así en la medida en que se agotaba su combustible para caracterizar el presente, se volvía más provechosa como temática al interior de los propios filmes.

El crítico estadounidense Godfrey Cheshire -leyendo el texto de Sontangpublica en New York Press una suerte de reunión de fragmentos profético-teóricos sobre el futuro inmediato del cine «The Death of Film/The Decay of Cinema» [La muerte del filme/La decadencia del cine] (1999). Este comienza relacionando las transformaciones que enfrentaría el cine, con una escena muy similar a la ola gigante que azota Nueva York en Deep Impact [Impacto profundo] (1998), de Mimi Leder. Esta fuerza devastadora se cristalizará en el siguiente fragmento:

Sometime within the next few years-it may take a decade or more, though a nearer date is more likely-the last commercial movie theater in the U.S. to adopt digital projection will make the switch, and the medium of film will reach its effective end. Thereafter, to see actual films displayed, as opposed to things that for a while may call themselves "films" but in fact are not, you will need to go to places like the Museum of Modern Art and the American Museum of the Moving Image, where projections of celluloid classics will probably remain very popular even while gaining an increasingly archaic air. (s/n pp. $)^{13}$

13 "En algún momento de los próximos años -esto puede tardar una década o más, aunque una fecha próxima es más probable- la última sala comercial de cine en los EE.UU. adopte la proyección digital hará que el interruptor y el medio fílmico llegue a su fin de manera efectiva. A partir de entonces, para ver proyecciones de las películas actuales, a diferencia de lo que por un tiempo podrán llamarse «cine» pero en efecto no lo es, usted tendrá que ir a lugares como el Museo de Arte Moderno y el Museo Americano de la Imagen en Movimiento, donde las proyecciones de clásicos del celuloide serán probablemente muy populares, aún cuando ganen un aire cada vez más arcaico". 
Estas transformaciones cambiarán profundamente las formas de comercialización cinematográficas, ya no se necesitará del celuloide, bajando con ello los costes de traslado y mantención de las películas, en la medida en que las transmisiones serán vía satélite, en una especie de glorificación del sistema de proyección de video doméstico. Pero aún más, la imagen digital cinematográfica según Cheshire se acerca mucho más a la imagen televisiva que a la del celuloide y apoyándose en algunos planteamientos del crítico Roger Ebert que planteaba que ambas imágenes contenían una diferencia sustancial. El cine en celuloide coloca al cerebro de un espectador en un estado de alerta, dominado por las ondas beta, mientras la televisión colocan al cerebro en un estado de lucidez relajada sujeto a una sugestión pasiva, dominado por las ondas alfa. Lo que implicaría una transformación radical de las formas en que nos enfrentaríamos a las nuevas imágenes en movimiento digitales.

A pesar de ello, nada iba a poder detener las transformaciones que se estaban gestando en el ceno de la industria cinematográfica, las cuales iban a implicar unos costes altísimos en la reconversión digital, que sería pasado directamente a los consumidores de cine, aumentando de las entradas pero también de las «palomitas de maíz». Pero también nada podría asegurar que esto iba traer una especie de democratización de la producción, en la famosa idea de que una película hecha en el patio de tu casa se iba a transformar en un éxito de taquilla en las pantallas de todo el mundo. Para Cheshire estaremos más cerca de una televisión maximizada, tanto en sus formas estéticas como en las manos que las producen. Por ello no será de extrañar que las salas cinematográficas puedan transmitir en directo, tal cual lo hacen las televisoras actuales, aquellos sucesos televisivos que puedan convocar a las masas del mundo, por ejemplo, el último capítulo de una serie con altos niveles de audiencia. Esto está a un paso de infinitas posibilidades de interactividad a través de Internet, la telefonía móvil y las transmisiones en directo: largometrajes interactivos, videojuegos colectivos y los más intensos paseos 3-D por el mundo. Este mundo digital auguraría también un mayor control de la «libertad» creativa de los «cineastas autores», que si no se desplazan a producciones de bajo presupuesto, estarán mucho más controlados, sobre todo considerando las facilidades de cambiar muchas veces la forma final de una película, si ésta no ha logrado los rendimientos económicos necesarios. Lo que a su vez podría transformarse en el infierno de los historiadores y museólogos cinematográficos. Por ello, "it’s far more reasonable to assume that digital technology's greatest impact on the movies will happen not at the least expensive levels of production but at the most expensive" (Cheshire s/n pp.) ${ }^{14}$.

Este escenario irá transformando gradualmente todas las esferas del cine (las formas narrativas, estéticas y formatos terminarán por modificarse completamente) y pasado el suficiente tiempo este tipo de espectáculo nunca más podrá llamarse

14 "es mucho más razonable suponer que el mayor impacto de la tecnología digital en las películas no pasará en los niveles más económicos de la producción, sino en los más caros". 
cine, no tendrá las características del mismo, esos rasgos definitorios que vinculan directamente el celuloide con el cine, aunque por un tiempo no se note la diferencia y terminará por cuajar que no funcionan de la misma forma. Así "one function that will accompany film into the museums, I think, is cinema, a peculiar kind of storytelling technological art that has reigned widely and gloriously through most of the 20th century" (Cheshire s/n pp.) ${ }^{15}$. Cheshire en este punto generará su más arriesgada profecía y en ella su muerte definitiva, planteando que algún día a una persona que conoció el cine en celuloide, se le parará a su lado un chico nacido en el nuevo milenio y le dirá "who you are: a 20-century person. A film person. In a world that has left that time and that technology behind" (s/n pp. $)^{16}$.

Gran parte del problema de la muerte del cine en la década del ochenta y noventa, se leyó en los parámetros más o menos citados anteriormente. 1) El agotamiento de sus formas estéticas a las manos de las formas de lo televisual: televisión, publicidad y videoclip. 2) Las desaparición de la experiencia cinematográfica en las salas con la aparición de los multicines, el video casero y su transformación digital en potencia, con ello el deceso de su religión: la cinefilia. Por esto, nos interesa incorporar dos lecturas antagónicas pero que nos propone perspectivas muy distintas sobre el óbito cinematográfico y que tendrán en común que de alguna forma sintomatizan una lectura sobre la muerte del cine mediado por una concepción del cuerpo. El primero es el artículo de Matthew Witt, en The death(s) of cinema according Godard [La muerte(s) del cine de acuerdo con Godard] (1999) publicado en la revista Screen, que intenta interpretar hasta las últimas consecuencias y pensar críticamente la frase de Godard, "Et je pense que je mourrai probablement en meme temps que le cinema, tel qu'il s'est invente.. L'existence du cinema ne peut exceder, a peu pres, la duree d'une vie humaine entre quatrevingts et cent vingt ans. C'est quelque chose qui aura ete passager ephemere" (cit. en Witt 332) ${ }^{17}$. El segundo es el libro-ensayo La muerte del cine (1999) que piensa en la materialidad del cuerpo de las imágenes cinematográficas, en su relación interna con el fenómeno teórico de la desaparición y lo efímero, escrito por Paolo Cherchi Usai. En éste no se pregunta por los tópicos estéticos del cine sino por la cuestión de la muerte como constitución esencial de su memoria y la constitución de su historia.

El artículo de Witt parte vinculando la lectura de la muerte del cine con el propio cuerpo de Godard, para desde ahí desplazarse por los distintos momentos mortuorios del cine que se figuran en el ideario godariano. El primero lo ubica en la interrupción de la exploración formal que estaba sucediendo en el cine mudo tras la instauración del cine sonoro. Aquí se vería la intensidad de la idealización de Godard por la producción

15 "una función que acompañará a la película al interior del museo, yo pienso, es el cine, una forma peculiar de arte tecnológico de contar historias que ha reinado ampliamente y atravesado gloriosamente la mayor parte del siglo XX".

16 "quien eres tú: una persona del siglo XX. Un persona film. En un mundo que ha dejado atrás el tiempo y la tecnología".

17 "Yo he pensado que moriré al mismo tiempo que el cine, tal como él fue inventado... La existencia del cine no puede exceder, más o menos, la duración de una vida humana entre ochenta y ciento veinte años. Es algo que ha sido pasajero, efímero". 
muda, pero, a su vez, la conexión que tendría éste con la tesis del historiador francés Pierre Leprohon. Según Witt éste sostiene que el «cine arte mudo» "was violently usurped and replanced by another different (and inherently inferior) form of cinema" $(334)^{18}$. La segunda muerte se encontraría cuando el cine ve el rostro del genocidio del pueblo Judío por parte de los Nazis en el Holocausto. Desde esta perspectiva, si el cine ha muerto lo que deviene -tanto para la obra de Godard, pero por extensión para el resto de las producciones- "is a graveyard, peppered with image-tombstones of those who have «died in action»" $(334)^{19}$. También se encontraría aquella muerte relacionada con el agotamiento del movimiento radicales que llamaban a destruir el cine "as a reactionary cultural form and purveyor of sanitized bourgeois myths and cliches" $(335)^{20}$, tanto en el slogan: «Fin de cinema», inscrito hacia el final de su filme Week-end (1967), pero también en el gesto anterior de Roger Boussinot que llamó, en Le Cinema est mort, vive le cinema [El cine ha muerto, viva el cine] a la ejecución del cine en sus formas industriales. La última muerte es aquella que acontece en las manos de las transformaciones de lo «televisual», que llevará aparejada una degradación de la cultural visual global. Así para Godard, según Witt, "the principal dislocation to cultural practice, indeed to daily life, has come less from militant politics than from what Godard repeatedly dubs the «explosion» of television, with its resultant catastrophic impact on daily life, and on cinema in particular" $(336)^{21}$.

Si bien, Witt avanzará críticamente en los detalles de este tránsito mortuorio -poniendo bajo sospecha las estrategias audiovisuales y dispositivos discursivos instalados por Godard-, este trayecto se transforma también en una forma de lectura de la propia historia del cine, comprendida entonces en una serie de movimientos epocales que a través de una violencia estructural agotan otras formas de cine, destruyendo cualquier posibilidad de presente. No obstante, la muerte asechada por lo televisual -en las imágenes de Godard- tiene un carácter definitivo, "the disintegration of an art form being eaten away from within by the proliferation of homogenized conventional (televisual) images" (336) ${ }^{22}$. Así le es posible a Witt volver a la metáfora corporal a propósito de las propias películas de Godard, en las cuales algunas veces su propio cuerpo las protagoniza, "the present day the cinema image is eaten away by electronic tumours" $(336)^{23}$.

Frente a esto, la muerte cinematográfica que está fraguando Cherchi Usai se muestra muy lejana, éste la planteó en una doble perspectiva, por un lado, no existe ninguna posibilidad material -como tampoco una perspectiva global ni mancomunada

18 "fue violentamente usurpado y remplazado por otra forma diferente (e inherentemente inferior) de cine".

19 "es un cementerio, salpicado de imágenes-tumbas de aquellos que han «muerto en acción»".

20 "como una forma cultural reaccionaria y proveedora de asépticos mitos y clichés burgueses".

21 "la dislocación principal de la práctica cultural, de verdad en la vida cotidiana, ha venido menos desde la política militante que de lo que Godard apoda la «explosión» de la televisión, con su consiguiente impacto catastrófico en la vida cotidiana, y en el cine en particular".

22 "la desintegración de una forma de arte siendo devorada desde dentro por la proliferación de imágenes convencionales homogeneizadas (televisuales)".

23 "la actualidad de las imágenes de cine está devorada por tumores electrónicos". 
al interior del campo del cine- de salvaguardar millares de imágenes en movimiento que se producen y se han producido hasta la fecha. Lo cual está vinculado directamente a que su propio procedimiento de captura e exhibición es aquella que condenan materialmente a esas imágenes en movimiento, desde rayaduras y rizamientos del material fotoquímico hasta la temperatura o la humedad que van deteriorándola -situación, con otros factores, que se repetirá para los distintos soportes de la imagen digital-. Este proceso que es intrínseco al cine -más que en ningún otro arte- coloca al espectador como "testigo inconsciente (a veces resignado, en cualquier caso impotente) de la extinción de imágenes en movimiento que nadie se preocupa en preservar porque se las considera indignas [XXXVIII] o inadecuadas para una futura explotación comercial" (Cherchi Usai 17).

Así - para Cherchi Usai- la Historia del cine tiene una doble función, por un lado, hacerse cargo de recuperar el contexto cultural de esas imágenes en un tiempo y sitio específicos y, por otro, reconstruir la experiencia de los espectadores de esas imágenes que se han desvanecido. "Las diversas condiciones que determinan esta pérdida crean la necesidad de establecer periodizaciones en la historia de la destrucción de la imagen en movimiento y en los esfuerzos humanos por destruir imágenes en general" (21). En última instancia, "la historia del cine es hacer la relación de su propia desaparición, o de su transformación en otra entidad” (89). En este sentido, se podría ampliar la comprensión del propio proceso que hemos intentado aprehender, si la historiografía del cine viene a pensar los distintos momentos de su destrucción, el óbito anunciado por Sontang y sistematizado por Gubern, no es sino el reconocimiento de un momento de declive de una forma de experiencia del cine. Y en ello la necesidad de reconstruir esa relación «erótica-meditativa» del cine. "La muerte del cine es ante todo un fenómeno mental que se producirá tantos si los factores mencionados en [IV] tienen realmente lugar como si no, y será sancionado por la tendencia natural a olvidar la experimentación del placer" (93).

Pero la muerte en el cine va más allá de esto para Cherchi Usai, este establece una relación interna de la propia imagen en movimiento con la muerte, ya que han establecido un pacto con lo evanescente, lo cotidiano, aquello que nada tenía de importante y que estaba sujeto al olvido. Éstas "surgen del propósito de transformar en objeto todo lo que puede olvidarse y por ello está condenado a la disolución y a la desmemoria. La impermanencia de esos hechos tiene su contrapartida empírica en la imagen en movimiento y determinan su estatus como artefacto" (65). Así la memoria del cine está condenada por su perdurabilidad técnica -fotoquímica o digital- como, a su vez, por aquello donde posa la mirada. Cherchi Usai, en definitiva, establece el conflicto de la memoria y su historia como una imposibilidad inherente a su propio procedimiento, pero en ella ensaya constantemente posibilidades para sortearla. Así la muerte de lo cinematográfico está alojada en la propia imagen cinemática, su condena está en su propio procedimiento, de su estar en el mundo de las imágenes. 
No obstante ello, la multiplicidad de perspectivas de la muerte cinematográfica no se detuvieron con la entrada del nuevo milenio, muchas de los problemas ya visto volvieron a ponerse en escena, con nuevos puntos críticos o formas de comprensión de los mismos. En los números de marzo y abril del año 2000 la revista Sense of cinema publicó una colección de 5 ensayos de distintos autores titulados «Permanent Ghosts: Cinephilia in the age of Internet and video» [Fantasmas permanentes: la cinefilia en la edad de Internet y el video], en los cuales se revisaron las sentencias de Sontang. En abril del mismo año Cahiers du cinéma, sacó a la calle un número monográfico titulado «Aux frontières du cinéma» [En las fronteras del cine] y el 2001 la revista inglesa Sight and Sound, publicó en su número de octubre el debate «The future of film» [El futuro del filme], ambas se preguntaban sobre el devenir cinematográfico en las manos de la imagen técnica digital. Francis Ford Coppola en el Festival Internacional de Cine de San Sebastián (2002), acuñará la frase: «¡El celuloide ha muerto, larga vida al cine!», dando por muerto el cine análogo y renovando la frase de Boussinot.

Ese mismo año los ingenieros estadounidenses James Korris (ex director de Institute for Creative Technologies by University of Southern California-USC) y Michael Macedonia -pioneros en el diseño de plataformas de simulación militar adaptando tecnologías utilizadas en Hollywood y en la cooperación entre los grandes conglomerados hollywoodenses y el Departamento de Defensa de EE.UU.- publican el artículo «The end of Celluloid: Digital Cinema Emerges», vuelven a abrir los fuegos en el debate celuloide versus digital, repasando el escenario futuro del cine digital y una posible mejora sustancial de la experiencia cinematográfica en los hogares, "increasingly affordable technology will soon make the home viewing experience superior to watching films in a theater" $(98)^{24}$. No obstante ello, comprenden que las multisalas -ya no las salas que añoraba nostálgicamente Sontang- no morirán a pesar de los avances en la experiencia televisual, pero de todas formas estarán a merced de las mejoras que suponga el cine digital, como dando crédito de algunas de las profetizaciones de Cheshire.

Por otro lado, académico norteamericano John Belton se inscribió en aquellos que no daban total crédito a la revolución que prometía la tecnología digital, específicamente para el público. En su artículo, «Digital Cinema: A False Revolution» (2002), plateará tres puntos sustanciales: 1) Tras la irrupción de los efectos especiales generados por ordenador la imagen fotoquímica (fotográfica) se ha transformado en un objeto plástico y, de alguna forma, como lo ha planteado Lev Manovich ${ }^{25}$ se ha constituido como un subconjunto de la animación. Siendo este el primer paso a lo que posteriormente veremos con todas los nuevos formatos de grabación digital. 2)

24 "La tecnología cada vez más asequible pronto hará la experiencia de ver televisión en el hogar superior a la de ver películas en los cines".

25 El artículo que cita Belton es «What is Digital Cinema? Cinema, the Art of Index» [¿Qué es el cine digital? Cine, el arte del índice]. 
La experiencia para el publico no cambiarán sustancialmente la experiencia misma de ir al cine. 3) Toda esta revolución está dirigida principalmente al ámbito del consumo de imágenes audiovisuales en el ámbito doméstico. “The digital revolution was and is all about economics-all about marketing new digital consumer products to a new generation of consumers - all about the home electronics industry using the cinema to establish a product line with identifiable brand names for home entertainment systems" (Belton 100-1) ${ }^{26}$. Diez años más tarde publicará la introducción a un número dedicado al cine digital en la revista Film History, titulada «Introduction: Digital Cinema» [Introducción: Cine Digital] y reclamará que no se ha escrito aún el obituario del cine en $35 \mathrm{~mm}$. al constatar que la empresa Kodak se ha declarado en baca rota y las empresas Panavision y Arriflex han dejado de producir cámaras de $35 \mathrm{~mm}$.

Como vemos el problema de la muerte del cine se verá ampliado con la entrada de las tecnologías digitales y no se circunscribirá a la incapacidad material de sostener su memoria, en la crisis de su experiencia cinefílica ni tampoco con el declive del programa estético de la modernidad cinematográfica. La discusión retornará con fuerza en el advenimiento de lo digital y la puesta en caducidad de la relación ontológica entre cine y realidad, aquello que tanto rendimiento discursivo tuvo para el desarrollo del cine moderno, en su condición de signo índice. La discusión sobre la crisis del material fotosensible está resumida a grandes rasgos en el breve artículo «El cine ha muerto. ¡Viva la realidad... virtual!» (2004) del semiólogo español José María Paz Gago. Éste plantea de una forma un tanto esquemática -siguiendo las reflexiones del semiólogo chileno Rafael del Villar- que el desarrollo de la televisión ha estado asociado a suplantar el formato material del celuloide con el formato videográfico. Lo cual sólo ha podido acontecer definitivamente con la imagen-técnica digital, que ha posibilitado el desarrollo de una señal televisiva de alta definición.

Ahora bien, Paz Gago planteará que "lo verdaderamente trascendental ha sido la repercusión en el cine de esta tecnología digital, con la entrada masiva de la realidad virtual y la simulación tridimensional (3D) en la pantalla grande" (112-113), ya que cambiaría su condición de signo índice a icónico en las categorías trabajadas por Charles S. Peirce. En el estado fotoquímico del cine -junto a la fotografía-, éstos serían signos índices que se relacionan con el objeto representado de forma existencial y no referencial, por ello sería índices genuinos y no degenerados. La irrupción de la imagen sintética lo trastocaría todo transformando su relación con el objeto, que pasaría a ser de un icono puro o signos degenerados, porque constituyen el sistema de comunicación de la simulación. “[...] el cine electrónico [digital] que se convierte en signo de sí mismo, configurado por iconos puros, mera posibilidad hipotética de

26 "La revolución digital fue y es totalmente sobre economía -totalmente sobre la comercialización de nuevos productos digitales de consumo para una nueva generación de consumidores-, totalmente sobre la industria de electrónica para el hogar; usando el cine para establecer una línea de productos con marcas reconocibles para los sistemas de entretenimiento hogareño". 
signo, el más alto grado de signo degenerado, llega a llamarlo Peirce, al estar basado solamente en la categoría de la primariedad y no referirse a ningún objeto ni llevar a ninguna interpretación en el nivel de la tercereidad" (Paz Gago 122).

Pero las posibilidades de las plataformas digitales no se terminan aquí, en éstas se encuentran la apertura a una forma de expresión estética en la que se anula la diferencia entre espectador y obra, anulando toda posibilidad de comunicación en manos de las plataformas interactivas-virtuales. Ahí es cuando emerge un espectador que ya no es un mero receptor de un mensaje, sino que se transforma en un súperreceptor que ve intensificada su actividad espectorial. Frente a este panorama que se abre para las formas audiovisuales, el sistema artistotélico edificado por el cine, pero también sus estrategias de desmantelación del mismo, se muestran impotentes frente a un signo que habría sustituido la ficción por el engaño, la representación por la simulación. Así para Paz Gago se ha dado paso a "un nuevo sistema cuya sanción artística todavía está por hacer" (123), en el cual el cine es sólo pasado.

En un empeño similar al que estamos llevando a cabo nosotros, Stefan Jovanovic publica el artículo en dos parte, «The Ending(s) of Cinema: Notes on the Recurrent Demise of the Seventh Art» [Los fin(les) del cine: Notas sobre la desaparición recurrente del séptimo arte] en la revista canadiense Off Screen en 2003. Éste hace un repaso por parte importante de esta literatura mortuoria del cine, concentrándose principalmente en los textos de Godfrey Cheshire, Matthew Witt y Paolo Cherchi Usai. Hacia el final de la primera parte se pregunta por el sentido de ponerle fin al cine como pregunta retórica y para ello se apoya en las reflexiones del teórico literario Frank Kermode, el cual propone -según Jovanovic- que al interior de los relatos apocalípticos o con finales de grandes desastres en la modernidad, ya no se encuentra la idea de un fin como espacio de reunión colectiva excepcional, que posibilita romper las diferencias y reconciliarnos como especie, sino que más bien es un estado inmanente al presente, que se encuentra en todas partes y perpetuamente. En este sentido, el tópico de la «muerte del cine» aparece como una respuesta cultural a cierta ansiedad por el fin de siglo y a una suerte de desastre tecnológico que iba a traer consigo.

Desde esta comprensión Jovanovic leerá las discusiones sobre la «muerte del cine» en tres grandes perspectivas en la segunda parte de su artículo. La de «transición», es decir, aquella que hace una lectura lineal de la decadencia del formato fílmico, que por ende todo el ser en el tiempo [zeitgeist] del cine ha sido el proceso de su desaparición. La del «doble movimiento» de la historia del cine, que comprende el futuro del cine (en su disolución completa o una gran transformación) como un nuevo comienzo de su propio devenir, de hecho ahí donde se piensa el futuro se podrían encontrar respuestas para sus comienzos. En ello se empalma el inicio y final del cine de tal forma; que todo el transcurso entre ambos pareciese desvanecerse. Por último, aquella que es una pura «negación», que es imposible recuperar nada y su devenir es un puro proceso de obsolescencia material, destrucción constante de 
sus imágenes, desaparición de su memoria cultural, donde la metáfora no sería el de ruinas cinematográficas, sino como un cuerpo orgánico que desaparece después de su muerte, en esto existe una conexión directa con las reflexiones de Cherchi Usai.

Dentro de esta estrategia de lectura nos interesa rescatar algunos puntos que encuentra Jovanovic. Éste considera que hay que pensar contextualmente este proceso en la tensión resultante entre cine y televisión desde la década del cincuenta, en la "anxiety toward the possibility of losing its audience and its resultant obsolescence in the face of the newer medium" (s/n pp. $)^{27}$, el cual se podría definir a estas alturas como una suerte de larga transición hacia la consolidación de la imagen electrónica-numérica en la industria audiovisual. Aún así, esta tensión en los últimos años ha sido redefinida, ya no sólo en el problema de la experiencia de la sala de cine y el despoblamiento de la misma, sino que ambos medios se ven sujeto a profundas transformaciones en relación a las posibilidades supuestamente infinitas que otorgan los medios digitales, a la hora de pensar una cultura audiovisual abocada a las formas de su interactividad. La comprensión de la «muerte del cine» como un estado de transición, es pensado por Jovanovic en dos sentidos. La primera es como una transición tecnológica, que se haya mucho antes que la aparición de las cámaras de video en los años setenta y que se encuentra en una serie de prácticas y experimentos que desde el propio campo del cine preparaban la aparición del dispositivo televisivo ya desde la década de 1930.

According to Vito Zagarrio ${ }^{28}$, the period from the early 1930s to the mid-1950s was marked by a determined tendency toward the mutation, convergence and divergence of the two media, with large-screen TV technologies developing in the 1930s, a video-to-film system devised by Paramount around the same time, the designing of small 400-seat cinemas to accommodate both film and TV presentation in the 1940s, the broadcasting of live horse races at the Pantages theater in Los Angeles and of other live entertainment at Paramount's theaters in Chicago, and the proposed broadcasting of sporting events on TV systems to be installed in the theater chains of Loew-MGM, Fox and Warner. (Javanovic s/n pp. $)^{29}$

27 "ansiedad hacia la posibilidad de perder su audiencia y su obsolescencia en relación al medio más reciente".

28 El trabajo que cita Jovanovic de Vito Zagarrio es «Theseus and Ariadne: For a Counter-History of the CinemaTelevision Relationship?» [Teseo y Ariadna: Para una contra-historia de la relación cine-televisión?], en Elsaesser, Thomas y Hoffmann, Kay (eds.). Cinema futures: Cain, Abel or cable?: the screen arts in the digital age. Amsterdam: Amsterdam University Press, 1998.

29 "De acuerdo con Vito Zagarrio, el período desde inicios de la década de 1930 y mediados de la década de 1950 estuvo marcado por una tendencia determinada hacia la mutación, la convergencia y divergencia de ambos medios, con las tecnologías televisivas de pantalla-grande desarrolladas en la década de 1930, un sistema video-para-película idea por Paramount en la misma época, el diseño de pequeños cine de 400 asientos para acomodar tanto a la película como a las presentación televisiva en la década del 1940, la transmisión en vivo de carrera de caballos el teatro Pantages en Los Ángeles y otros entretenimientos en vivo en los teatros de la Paramount en Chicago, y la transmisión propuesta de eventos deportivos en sistemas televisivos para ser instalados en las cadenas de teatros de Loew-MGM, Fox y Warner". 
Resulta interesante que Jovanovic nos haga notar que existe algo similar entre este escenario descrito por Zagarrio y las proyecciones del futuro cinematográfico en Cheshire y otros. Habría que sumar a esto, que este último también genera un empalme entre el inicio de este nuevo futuro de las imágenes audiovisuales que no serán cine, con el inicio del propio cine en el siglo XIX, diciendo que la experiencia ante esas nuevas imágenes que veremos que no son cine, estaremos igual las primeras personas que vieron una película. "When people first saw film, they didn't see movies. This is pretty remarkable if you think of it. Imagine you're at one of the first projections of motion pictures, in 1895 or so. The projector whirs on, images flicker on the wall, and for a few seconds, maybe longer, you struggle to figure out just what the hell you're seeing. Is it one of those fairground illusions? Some new kind of illuminated painting? A camera obscura reflection from outside?" (Cheshire s/n pp.) ${ }^{30}$. No obstante ello, en Zagarrio lo ve como un proceso continuo de transformaciones tecnológicas, industriales y culturales de experimentación con las formas de exhibición cinematográficas, mientras Cheshire sólo lo ocupa de forma retórica para generar una quiebre definitivo entre el cine de celuloide y el audiovisual del futuro.

Ahora bien, la muerte del cine también puede ser comprendida en otra dimensión de transición según Jovanovic, que sería en el traspaso entre un sistema capitalista fordista a post-fordista de producción de bienes, es decir, una comprensión sistémica en que el cine correspondería en esencia a una modernidad del siglo XIX, pero que tuvo que vivir el largo proceso de transformación de las formas de producción del capital en el siglo XX, que en última instancia acabarían con su propia existencia cuando este proceso llegue a su fin. Idea que está sostenida en ideas como las de Jacques Aumont en El ojo interminable: cine y pintura (1989). "El cine es aún el siglo XIX en pleno siglo XX [... es la] Última de las artes, último lugar donde aún se juega algo parecido a una dialéctica entre creencia, imaginación y percepción difusa del material: último nivel del teatro en la pintura. El cine, o el último espacio imaginable" (164-7).

Más allá de esto nos interesa destacar que desde la estrategia reflexiva de Jovanovic se puede desprender que para pensar la muerte contemporánea del cine, se ha hecho necesario re-visitar la historia del propio cine para identificar que es lo que se ha muerto realmente del cine y con ello se han generado nuevas formas de lectura de este devenir los cuales pueden concluir o no con la ratificación de la muerte del cine, por ello Jovanovic re-afirmará repetidas veces el gesto contra-histórico de Zagarrio, por ejemplo. Esto es lo que le posibilitará comprender que estos mismos procesos han revitalizado a la propia producción cinematográfica, en el trabajo de artistas como Douglas Gordon o Mark Lewis, ya que en ellos se encuentran otras formas de com-

30 "Cuando la gente vio el primer material fílmico, ellos no vieron películas. Esto es bastante notable si se piensa en ello. Imagina que estás en una de las primeras proyecciones de imágenes en movimiento, en 1895 más o menos. El proyector gira zumbando, imágenes parpadean en la pared, y por unos segundos, tal vez más, luchas por averiguar que demonios estás viendo. ¿Es una de esas ilusiones de feria? ¿Un nuevo tipo de pintura iluminada? ¿Un reflejo de una cámara oscura desde fuera?” 
prender lo cinematográfico a través de estrategias de trabajo multimedia, que generan meditaciones muy profundas sobre el pasado y el futuro de las imágenes en movimiento. Así las transformaciones y muertes del cine son una plataforma para un despliegue productivo, disponiéndose de forma complementaria a las perspectivas de Brenez.

Retomando el hilo de los problemas acaecidos en torno a las transformaciones digitales, habría que volver por un momento a las implicancias que estás tendrían en las formas narrativas propias del cine. Peter Greenaway declaró en el Festival de Cine de Pusan (2007), que la muerte del cine ocurrió «el 31 de septiembre de 1983, cuando se introdujo el control remoto en el salón de estar de las casas», sin duda, el evento ubicado por Greenaway en esa fecha ficticia marca una de las reflexiones fundamentales de las críticas contemporáneas sobre la vitalidad cinematográfica actual, es decir, la interactividad nula existente en el cine y que se desborda en las nuevas plataformas virtuales, lo que condenaría el futuro cinematográfico a corto plazo, como ya lo leíamos en el texto de Cheshire. En 2006 David Bordwell se planteó abordar este problema en «The End of cinema as we know it-yet again» [El fin del cine como lo conocemos, una vez más]; a propósito de un artículo de Joe Morgenstern ${ }^{31}$ y The Onix Project [El Proyecto Onix] (2006), de David Strathairn. Ambos de distintas forma proponían que el presente reclama cada vez más formas narrativas audiovisuales no lineales, en que el espectador tiene que determinar el orden de los acontecimientos, colocándose así al nivel de los videos-juegos y muchas otras plataformas actuales que implican la interacción e intervención directa del espectador, que estarían destruyendo las formas narrativas del cine - The Onix Project es una pieza audiovisual en DVD que justamente posibilita que el espectador ordene la historia a su criterio-.

Bordwell cuestionará el argumento que supone una relación directa entre lo que se comprende como la fragmentación de la vida cotidiana -al cual apelan sus dos interlocutores- y la crisis de las formas narrativas cinematográficas. Si la fragmentación es la experiencia estética que se busca en la contemporaneidad y que, por ende, se exige a las nuevas formas cinematográficas, Bordwell se pregunta por qué no son exitosos filmes como Caché (2005), de Michael Haneke, o Memento (2000), de Christopher Nolan, cuando por lo contrario, los éxitos de taquilla se encuentra en filmes como Pirates of the Caribbean: Dead Man's Chest [Piratas del Caribe: El cofre del hombre muerto] (2006), de Gore Verbinski, en la trilogía de The Lord of the Rings [El señor de los anillos], de Peter Jackson, etcétera. Si bien, existiría una mayor sensación de vivir un mundo fragmentado -incluso caótico-, los productos culturales que más se consumen no responden a esa misma lógica y siguen siendo una parte menor dentro de las experiencias estéticas masivas. Por ello, Bordwell considera que todas esas apuestas audiovisuales alternativas, por ejemplo encarnadas en The Onix Project, "it

31 Bordwell hace referencia al artículo «Set the DVD Player to 'Random'» de Joe Morgenstern, publicado en Wall Street Journal el 28 de octubre de 2006. 
may usher in a new storytelling medium somewhere between films and videogames. If not, it will be the Clue of its day. Either way, most filmmakers in Hollywood and elsewhere will continue to try and make movies with stories that people can easily follow" (s/n pp.) $)^{32}$.

Finalmente, cuando Gilles Lipovetsky y Jean Serroy publican La pantalla global en el año 2007 y exponen su hipótesis de qué el cine contemporáneo no puede ser comprendido por fuera de los procesos de pantallización del mundo, justamente porque éste fue aquel que inauguró ese dispositivo inédito en el régimen del arte, que marcó profundamente el desarrollo cultural del siglo XX. Esta pantalla del cine que tenía una condición específica, no era sólo un espacio de proyección de imágenes, sino que ella se constituyó como el espacio privilegiado de espectacularización de los imaginarios sociales. Así esta pantalla hegemónica que abarcaba todo el espectro visible, donde el cine dominó el estado cultural gran parte del siglo XX, desde la aparición de la televisión y la expansión de las plataformas audiovisuales, virtuales y multimediales su estado de «unipantalla» que edificó un contexto cultural de la "pantalla espectáculo», se pasó a la «omnipantalla»-aquella que está en todos lados- en un contexto cultural de la «pantalla comunicación». Esta perdida hegemónica ha obligado a repensar al cine con muchas otras formas de producciones estéticas que se vehiculizan en múltiples pantallas, es decir, pensarlo como un género más al interior de la «pantallasfera».

A pesar de lo anterior Lipovetsky y Serroy no pudieron desprenderse de la pregunta de la muerte del cine, así que plantearon que lo único verdadero que ha traído ésta idea es la constatación de la desaparición del cine "clásico», a través de un profundo quiebre acaecido hacia finales de los años setenta e sobre todo en los años ochenta. Que a diferencias de transformaciones tecnológicas -muchísismas que ha vivido el cine en su historia- y rupturas estéticas anteriores que ha vivido el campo del cine, el estado contemporáneo cinematográfico es resultado de "una mutación de fondo que afecta todos sus dominios, a la producción como a la distribución, al consumo como a la estética fílmica. Los cambios son tales que nos permiten plantear la hipótesis de la aparición de un nuevo régimen histórico en el cine, una cinegalaxia. No el «fin del cine» sino la aparición de un hipercine" (Lipovetsky y Serroy 16). Este nuevo estado ha afectado al cine mundo por completo y no sólo a sectores específicos -como en rupturas anteriores-, abandonando la era moderna del cine, poniendo fin a un proceso medianamente continuo.

En ello encuentran una pujante vitalidad y en constante reinvención de sus formas, estrategias y discursos, que no ha visto mermado la cantidad de producciones ni la diversidad de las mismas, de hecho ha ido en constante aumento. Para Lipovetsky y Serroy “el «verdadero» cine no está detrás de nosotros, dado que no cesa de

32 "éste puede marcar un nuevo medio para contar historia, en algún lugar entre el cine y los videojuegos. Si no, será la Clave de su día. De cualquier manera, la mayoría de los cineastas de Hollywood y otros lugares continuará tratando y haciendo películas con historias la gente pueda seguir fácilmente". 
reinventarse" (12), vive una ebullición temática, que otrora era censurada por rígidos códigos morales y, a su vez, ha existido una amplia inclusión de mujeres realizadoras, filmes procedentes de múltiples lados y que cada vez resulta más representativo de una diversidad cultural, sexual, idiomática, generacional, etc. Entonces "lo que se avecina es un cine global fragmentado, de identidad plural y multiculturalista" (Lipovetsky y Serroy 15). El presente audiovisual en la proliferación de pantallas, redes, ordenadores, programas a la carta, televisión por paga, etc. se parece más al fin de la televisión que la desaparición televisual del cine. Ahora bien, la no hegemonía cinematográfica en el presente de la cultura de masas, en la cual está junto a muchos otros iguales o más que él, es aquello que en la perspectiva de Lipovetsky y Serroy -de forma similar Gubern- anuncia el triunfo simbólico del cine, ya que todos estos viven de su "imaginario: el del gran espectáculo, la puesta en imagen, el star-system" (24). El cine se ha transformado en la matriz simbólico-cultural de todos los que habitan afuera de él.

Este recorrido teórico da cuenta de un proceso donde el cine ha perdido el protagonismo cultural que le había dotado la modernidad, ya no es el depositario del horizonte simbólico de la contemporaneidad. "El cine ha perdido su lugar de privilegio y ha caído del pedestal, se ha entendido desnaturalizado, ha tomado conciencia de su fracaso; o sea, ha girado su ángulo de mirada hacia sí mismo en la medida en que no puede sostenerlo hacia la realidad, o por lo menos hacer la doble operación" (Santa Cruz G. 61). Así lo que se ha estado fraguando en su interior, es la imposibilidad de contener los sueños de las masas, como nos ha planteado Susan Buck-Morss a propósito de las configuraciones de las ciudades contemporáneas. "Los sueños se están divorciando del espacio de la ciudad [el cine]. El planteamiento urbano reciente ha estado más comprometido con la seguridad contra el crimen que con montar fantasmagorías para el deleite de las masas" (251). El cine ha terminado por caerse de ese pedestal que le había construido la modernidad cultural cuando las plataformas multimediales y televisivas comenzaron a inventar los mitos de la contemporaneidad.

No obstante ello y siguiendo la línea de lectura realizada por Brenez, se podría plantear que el tópico de la muerte del cine -esta obsesión teórica que ha protagonizado grandes pasajes de las últimas dos décadas-, ha sido un motivo que ha posibilitado muchas lecturas sobre el devenir y el pasado cinematográfico. Una especie de combustible que autoriza a entrar en espacios que los estudios de medios y de cine más hegemónicos habían negado. Abrieron las puertas a considerar al cine en un campo teórico expandido - parafraseando a Rosalind Krauss-, donde ha tenido que negociar sus conceptos pero también sus formas, pensándose al interior del régimen contemporáneo del arte. El cual paradójicamente para el propio cine -con sus expectativas 
de autonomía productiva- había transformado profundamente desde las primeras décadas del siglo XX. ¿Cómo se puede comprender el arte actual sin los problemas de la reproductibilidad? Es sólo una de las preguntas que se podrían esgrimir. Este campo expandido establece un espacio de negociación -pero también reconocimiento- conceptual con otras formas de producción audiovisuales, constituido en la tensión entre cine y televisión, video-arte y video-clip, pero también con nuevas formas de lo audiovisual.

Así gran parte de las discusiones citadas han sido la condición de posibilidad para desplazamientos teóricos; que han pensado al cine en un campo de producción híbrida en los conceptos de entre-imágenes, post-cine o condición post-medial, repensando sus fronteras institucionales en su relación con el museo cuando apela al cine de exposición, cine de artistas, «screen art», paracinema y «moving image experence» o en la recuperación de conceptos como cine expandido de las vanguardias cinematográficas de las décadas de 1960 y 1970 y publicaciones como Film Culture de Adelfas y Jonas Mekas. La aparición del espacio museístico Solar, Galería de Arte Cinemática en el contexto del Festival Curtas en Villa del Conde-Portugal funcionando desde 2002. A su vez, posibilitado múltiples proyectos expositivos: Passages de limage [Pasajes de la imagen] (19 de septiembre de 1990 a 13 de enero de 1991), comisariada por Raymond Bellour, Catherine van Assche y Catherine David en el Centro Pompidou-Paris. Future Cinema. The Cinematic Imaginary after Film [Cine futuro: El imaginario cinematográfico después del filme] (2002-2003), comisariada por Jeffrey Shaw y Peter Weibel en el Centro de Arte y Medios Karlsruhe-ZKM, Alemania. Correspondencias: Víctor Erice y Abbas Kiarostami (2006), comisariada por Alain Bergala y Jordi Balló en el Centro de Cultura Contemporánea de Barcelona-CCCB. La participación curatorial de Alexander Horwath, crítico cinematográfico y actual director del Museo del Cine de Austria, en el encuentro Documenta-Kasel del 2007. La pantalla global (2012), comisariada por Jean Serroy, Gilles Lipovetsky y Andrés Hispano, en el Centro de Cultura Contemporánea de Barcelona-CCCB, por nombrar algunos pocos ejemplos.

A esto hay que agregarle proyectos textuales como El ojo interminable: cine y pintura (1989), de Jacques Aumont, Entre-imágenes (1990) y L'Entre-images 2 (1999), de Raymond Bellour, Cinéma dexposition: lespacement de la durée [Cine de exposición: el espaciamiento de la duración] (2002), de Jean-Christophe Royoux, The Cinematic. Documents of Contemporary Art [Lo cinematográfico. Documentos de arte contemporáneo] (2007), editado por el artista inglés David Campany, Art and the moving image: A critical reader [Arte y la imagen movimiento: un lectura crítica] (2008), editado por Tanya Leighton, The Place of Artists' Cinema. Space, Site and Screen [El lugar del cine de artista. Espacio, sitio y pantalla] (2009), de Maeve Connolly, Después del cine. Imagen y realidad en la era digital (2011), de Ángel Quintana o Puntos de encuentro en la iconosfera. Interacciones en el audiovisual (2013), editado por Antoni Mercader y Rafael Suárez. Números monográficos en diversas revistas como «Le cinéma après les films» [El cine después de las películas] (2000) en ArtPress $\mathrm{N}^{\circ} 262$, «El cine se instala en el museo» (2006) en Exit Express № 20, «El cine en el espacio del arte» (2010) en 
Secuencias. Revista de Historia del cine № 32, «The Militant Image: A Ciné-Geography» [La imagen militante: Un cine-geografía] (2011) en Third Text № 108.

Todo esto también ha estado acompañado por la idea de que la historia del cine se ha escrito sólo en la medida en que la industria lo ha permitido. Ausentando en ello una serie de obras fundamentales, que por falta de notoriedad pública carecen de un lugar real en el devenir cinematográfico, colocadas en una marginalización sustentada en su escaso impacto masivo. Para la ya citada Brenez, "la historia del cine debe separarse de la historia del comercio y la sociología, con las que demasiado a menudo se las confunde hoy en día" (en Rosenbaum y Martin 306), se hace necesario generar una historia «verídica» del cine, que ponga al centro a las formas del cine. Esto se ha ido multiplicando y generando nuevas formas de leer el devenir cinematográfico, todo eso que ha sido censurado u olvidado por las narrativas hegemónicas que ponen como eje del cine la historia de Hollywood y las resistencias que generó en Europa. Ejemplo de esto lo encontramos en el propio proyecto de Brenez de recuperar a aquellos cineastas militantes en movimientos subversivos o guerrilleros que buscaban la transformación política de la sociedad, que se ha concretado en una película hecha en colaboración con Philippe Grandrieux, sobre el cineasta japonés Masao Adachi, el cual en la década del setenta se unió al Ejército Rojo Japonés-Nihon Sekigun, película titulada Il se peut que la beauté ait renforcé notre résolution - Masao Adachi [Si quizás la belleza ha reforzado nuestra convicción-Masao Adachi] (2011).

En definitiva la muerte del cine fue un tópico de profunda vitalidad teórica que expandió los límites de la teoría cinematográfica y lo concibió en un territorio más amplio de prácticas audiovisuales, pero aún más, todavía es un motor reflexivo para el presente, el cual no ha terminado por evaluar las rápidas transformaciones en las cuales se ven inmersas las producciones culturales y artísticas. Así y retomando la idea de Witt de que para Godard el cine «es un cementerio, salpicado de imágenes-tumbas», el cual parece estar como en pausa, infértil, sin futuro alguno más que como un lugar de visitas nostálgicas, pero mientras uno se introduce entre las calles o senderos de ese cementerio -como de cualquier otro en el mundo- uno se termina encontrando en un espacio lleno de vida. Ahí donde el cine «porque se consideraba el más grande, siempre se creyó el más efímero»-como dijo De Baecque -.

\section{Referencias}

Aumont, Jacques. El ojo interminable: cine y pintura. Barcelona: Ediciones Paidós Ibérica, 1997. Medio impreso.

Belton, John. «Digital Cinema: A False Revolution». October 100 (2002), 99-114. Medio impreso.

Bordwell, David. «The End of cinema as we know it-yet again». David Bordwell's website on cinema, 2006. Sitio web. Fecha de ingreso: 11 de marzo de 2013. 
Buck-Morss, Susan. Walter Benjamin, escritor revolucionario. Buenos Aires: Interzona Editora, 2005. Medio impreso.

Cherchi Usai, Paolo. La muerte del cine. Historia y memoria cultural en el medioevo digital. Barcelona: Editorial Laertes, 2005. Medio impreso.

Cheshire, Godfrey. «The Death of Film/The Decay of Cinema». New York Press, revista virtual, 1999. Sitio web. Fecha de ingreso: 10 de marzo de 2013.

Daney, Sergei. (1987) «Pour une ciné-démographie». Serge Daney in English, blog, 2008. Sitio web. Fecha de ingreso: 30 de mayo de 2012.

---. «From movie to moving». Art and the Moving Image. Ed. Tanya Leighton. Londres: Tate Publishing, 2008. 334-339. Medio impreso.

De Baecque, Antoine. «Mort du cinema», Evene.fr, revista virtual. Sitio web, 2012. Fecha de ingreso: 10 de mayo de 2013.

Elsaesser, Thomas (1992). «Around Painting and the «End of Cinema» - A Propos Jacques Rivette's La Belle Noiseuse». Order of the Exile, www.jacques-rivette. com. Sito dedicado al cineasta Jacques Rivette, sin año. Sitio Web. Fecha de ingreso: 23 de abril de 2013.

Gubern, Román. «El cine después del cine». Historia general del cine XII: El cine en la era audiovisual. Ed. Manuel Palacios y Santos Zunzunegui. Madrid: Ediciones Cátedra, 1995. 289-309. Medio impreso.

Jovanovic, Stefan. "The Ending(s) of Cinema: Notes on the Recurrent Demise of the Seventh Art. (Part 1 and Part 2)». Off Screen, revista virtual, 2003. Sitio web. Fecha de ingreso: 20 de abril 2013.

Korris, James y Michael Macedonia. «The end of Celluloid: Digital Cinema Emerges», Computer 35. Vol. 4 (2002). 96-98. Medio impreso.

Lipovetsky, Gilles y Jean Serroy. La pantalla global. Cultura mediática y cine en la era hipermoderna. Barcelona: Editorial Anagrama, 2009. Medio impreso.

Paz Gago, José María. «El cine ha muerto. ¡Viva la realidad... virtual!». Arte y nuevas tecnologías: X Congreso de la Asociación Española de Semiótica. Coor. Miguel Ángel Muro Munilla. Logroño: Universidad de La Rioja y Fundación San Millán de la Cogolla, 2004. 110-25. Medio impreso.

Rosenbaum, Jonathan y Adrian Martin. Mutaciones del cine contemporáneo. Buenos Aires: Errata Nature editores, 2010. Medio impreso.

Santa Cruz G., José M. Imagen-Simulacro, estudios de cine contemporáneo (1). Santiago de Chile, Ediciones Metales Pesados, 2010. Medio impreso.

Sontang, Susan. «The Decay of Cinema». New York Times, diario virtual, 25 Febrero 1996. Sitio web. Fecha de ingreso: 21 de noviembre de 2011.

Witt, Matthew. «The death(s) of cinema according Godard». Screen 40, Vol. 3 (1999). 331-46. Medio impreso.

Recibido: 28 mayo 2013 Aceptado: 23 noviembre 2013 